\title{
IOT based application for monitoring electricity power consumption in home appliances
}

\author{
Korakot Luechaphonthara, Vijayalakshmi A \\ Department of Computer Science, CHRIST (Deemed To Be University), India
}

\begin{tabular}{l}
\hline \hline Article Info \\
\hline Article history: \\
Received Dec 20, 2018 \\
Revised Apr 17, 2019 \\
Accepted Jun 26, 2019 \\
\hline
\end{tabular}

\section{Keywords:}

Current sensor

Electricity monitoring

Internet of things

\begin{abstract}
Internet of Things is one of the emerging techniques that help in bridging the gap between the physical and cyber world. In the Internet of Things, the different smart objects connected, communicate with each other, data is gathered from the smart objects and based on the need of the users, and the data gathered are queried and sent back to the user. IoT helps in monitoring electrical and physical parameters. Electricity consumption from electronic devices is one among such parameters that need to be monitored. The development of energy efficient schemes for the IoT is a challenging issue as the IoT becomes more complex due to its large scale the current techniques of wireless sensor networks cannot be applied directly to the IoT. To achieve the green networked IoT, this paper proposes a Wi-Fi enabled simple low cost electricity monitoring device that can monitor the electricity consumption on home appliances which helps to analyses the consumption of electricity on a daily and weekly basis.
\end{abstract}

Copyright (C) 2019 Institute of Advanced Engineering and Science. All rights reserved.

\section{Corresponding Author:}

Korakot Luechaphonthara,

Department of Computer Science,

CHRIST (Deemed To Be University),

Bangalore, India.

Email: Korakot.luechaphonthara@cs.christuniversity.in

\section{INTRODUCTION}

Internet of Things (IoT) gathers useful data by integrating sensing and communication capabilities between different devices. Advancements in this field have opened a wide range of possibilities in the design of future smart homes. These devices are very much useful in monitoring and analyzing various physical and environmental parameters remotely. IoT enabled electricity consumption devices to monitor the amount of electricity consumed by home appliances will help individuals to understand and analyze the amount of electricity consumed by each appliance at home. As devices can be connected wirelessly and data can be remotely accessed, these devices are gaining popularity rapidly.

As electricity consumption is increasing day by day, the cost of it also is increasing thus; consumers are interested in reducing their consumption in electricity. There are devices available in market that helps in monitoring and saving energy consumption in home appliances. These devices help in monitoring the amount of electricity consumed by different devices. In [1] room architecture is designed to reduce power consumption.

In India, the conventional electrical meters provided by the electricity suppliers measure the power consumption of a building for a month and provide the reading of a month to the consumers. In this case, consumer is not able to observe and monitor the electricity consumption per day per appliances in his building/home. Using electricity meters, the electricity consumption of different appliances can be monitored individually and controlled if required. This will help the consumer to identify the major consumption of electricity with respect to any appliance and can take appropriate measures that will in turn help 
the environment. Using an electricity meter that could measure the power consumption of individual appliances separately, can help consumers control electricity consumption.

A ZigBee control module is used in [2] which consist of a circuit for sensing the current. This sensed module sends back current that is measured and sends a message if there is an overload. Smart electricity meters have been developed but has disadvantages like high cost, installation difficulty etc. We have addressed these issues in this work by implementing a low cost and less complex design of an electricity monitoring device that provides automated load energy reading over. The device implemented has a Wi-Fi module embedded that uses wireless network to send the power consumption data to the cloud server for storage and further monitoring. Consumer can retrieve the data stored in the cloud server using a computer or smart phone over internet.

There are several methods developed for monitoring electricity consumption in household appliances [3]. Activity pattern is enabled for appliances at home in [4, 5]. Consumers behavior is assessed and looked into based on surveys in [6]. Some of the studies in literature used household appliances to monitor the electricity consumption [7-9].

\section{METHODOLOGY}

The Figure 1 represents the architecture of the proposed system. The proposed system consists of two major technical components, information acquisition and information presenting. Sensors measure the actual power consumption and transmit this information to the information processing module via the $\mathrm{Wi}$-Fi module. When the information processing module receives the power consumption information it stores them into a database. The database used is MySQL in AWS cloud server.

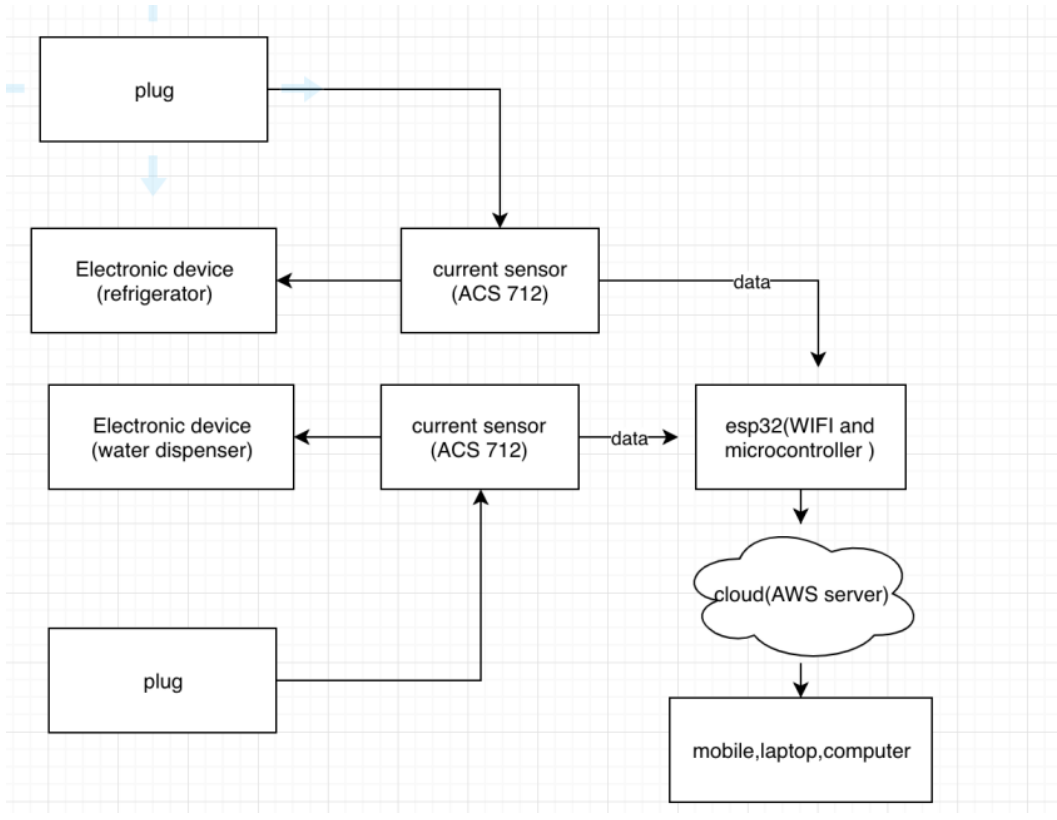

Figure 1. Architectural design for the proposed work

The next module that is the module for Data processing receives the information on the electricity consumption that is sensed from each of the sensor placed for the appliance through a Wi-Fi communication interface. Further, this information is stored in the MySQL database and can respond to the requests from users. A web server in it receives users' service requests and transfers them to the sub-technical components. The final goal of the proposed system is to provide users with smart services with monitoring energy consumption. Figure 2 show data store design from the sensors.

ESP8266 is used for controlling the sensors, monitoring and analyzing. The reason for using ESP8266 is because of its low cost, the embedded Wi-Fi module chip which helps in connecting to the Internet for Internet of Things (IoT). The sensor used for sensing current is the Current Sensor (ACS712). The ACS712 Current Sensors are designed to be easily used and they are offered with full scale values of 5A, 20A and 30A. The basic functional operation of each of these devices is identical. The only 
difference is with the scale factor at the output. The sensor can measure positive and negative currents (range $-5 \mathrm{~A} . .5 \mathrm{~A})$, and power supply is $5 \mathrm{~V}$ for the sensor, and the middle sensing voltage is $2.5 \mathrm{~V}$ when no current. This current sensor gives precise current measurement for both AC and DC signals. Figure 3 show AC current signal.

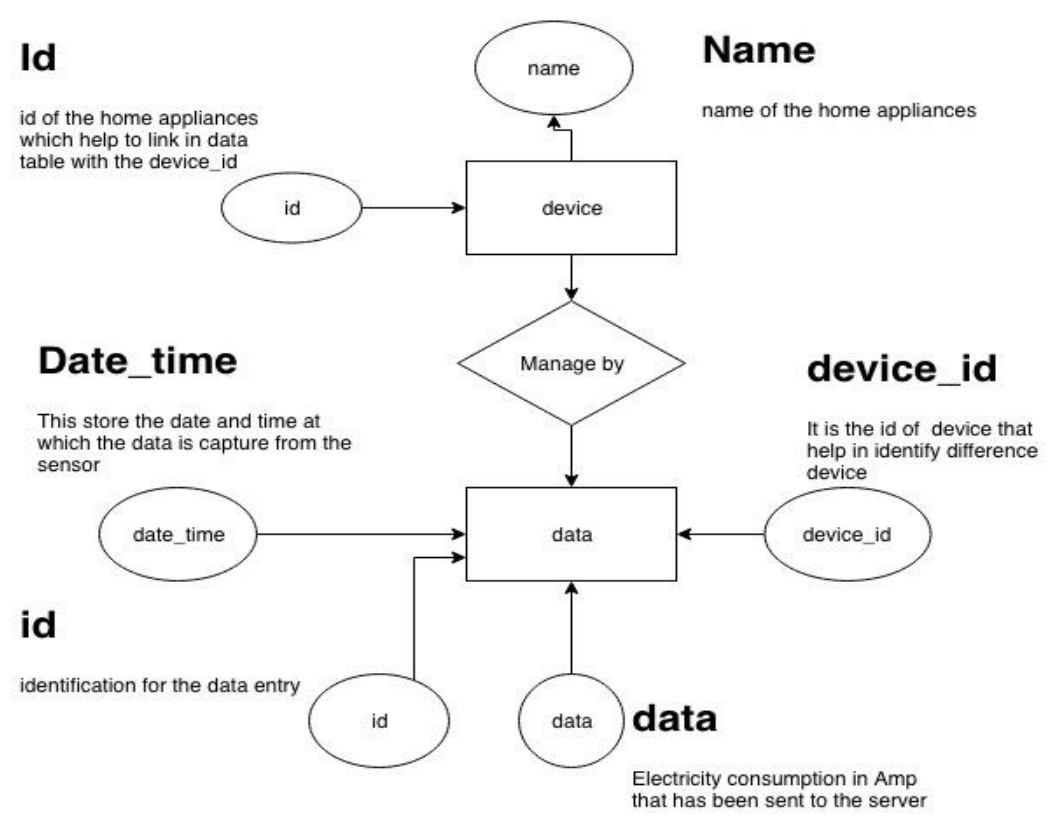

Figure 2. Data store design from the sensors

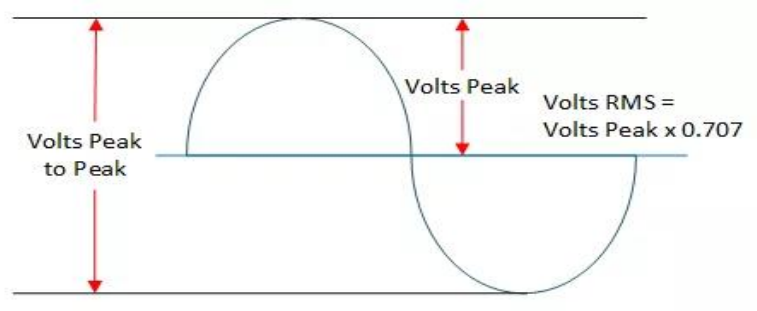

Figure 3. AC current signal

\subsection{Finding the RMS value}

In most cases, an expression of AC current will be in a value known as RMS. In order to use the ACS712 current sensor to measure AC current, it is important to understand how to calculate an RMS current value from the device readings. To calculate the RMS volts and apply the ACS712 scale factor, conversion for a sine wave with a zero volt offset (like your mains or line power) is performed as follows.

Step 1: Find the peak to peak voltage (Volts Peak to Peak)

Step 2: Divide the peak to peak voltage by two to get peak voltage (Volts Peak)

Step 3: Multiply the peak voltage by 0.707 to yield rms volts (Volts RMS)

\section{RESULTS AND ANALYSIS}

Electricity meter was connected to following appliances to collect electricity consumption data over a period of 6 weeks continuously in an existing residence of 4 persons in Bangalore, India. The data collected are classified into day and night. 6 am to $6 \mathrm{pm}$ is considered as day time and $6 \mathrm{pm}$ to 6 am is taken as the night period. The appliances from which data was collected were 1 . Refrigerator and 2 . water dispenser. 
Figure 4 shows the amount of electricity consumed by the two appliances at day time and at night. From Figure 4 it is clear that the amount of electricity consumed is greater at night times compared to day. Monitoring the real time data on energy consumption, the consumer can reduce the usage of the appliances at night time. Figure 5 represents the overall energy consumption for the two appliances day wise. From the figure, it is clear that the electricity consumption at the weekends are much higher than week days.

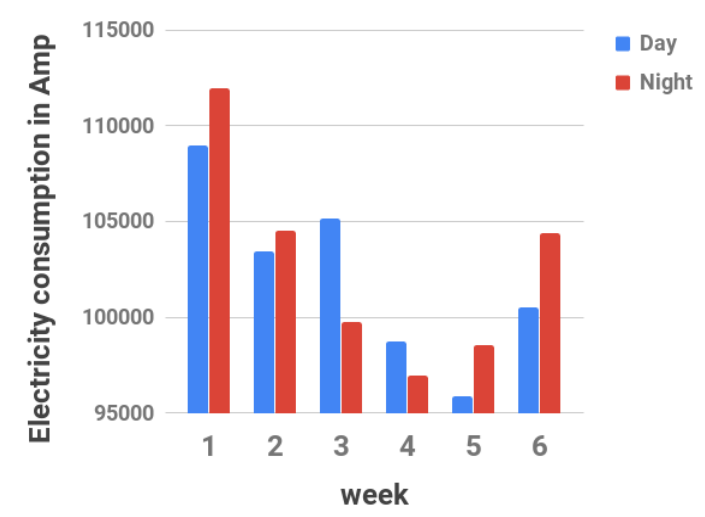

Figure 4. Overall energy consumption at day and night

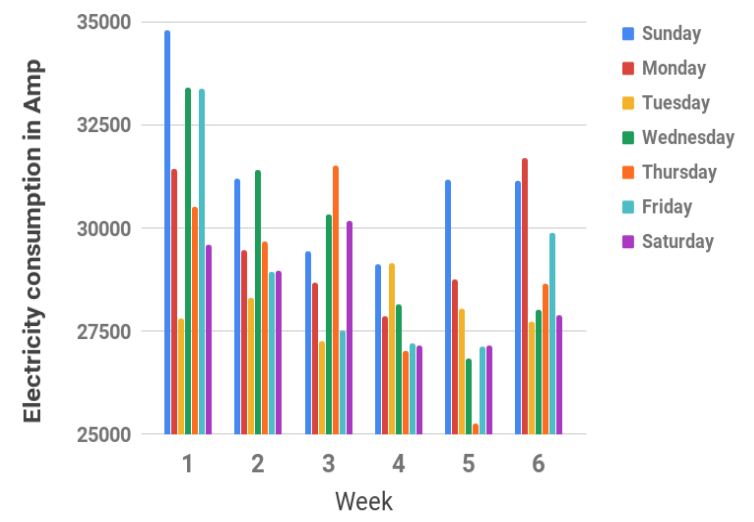

Figure 5. Overall energy consumption day wise

Considering the water dispenser separately, to have an analysis or monitor on the amount of electricity consumed, Figure 6 shows the amount of electricity consumption at day and night times. From Figure 6, it can be concluded that on an average, water dispenser consumes more energy at night times compared to day time.

The electricity consumption is analyzed day wise for six weeks. It was analyzed that the electricity consumption is higher in the weekends compared to week days. Figure 7 represents the electricity consumption of second appliance considered for the study, the refrigerator. The figure we can see that on an average, the amount of electricity consumed at night times is greater than day times. An exception is given for week 4 as the members were not present at home that week at night times.

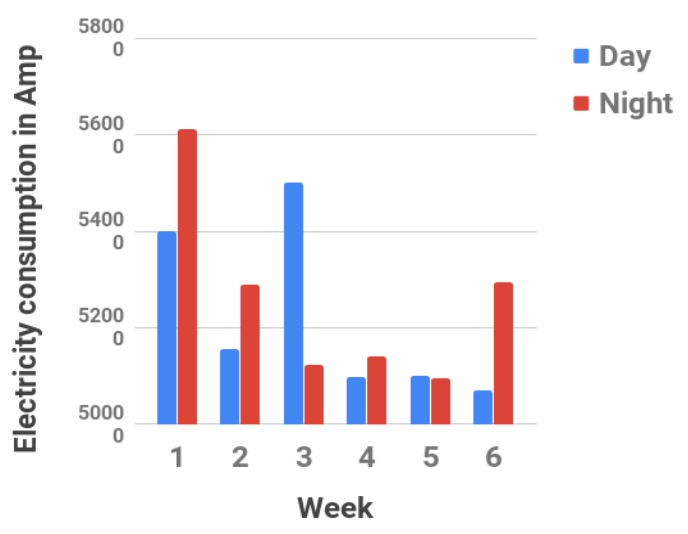

Figure 6. Energy consumption of water dispenser day and night

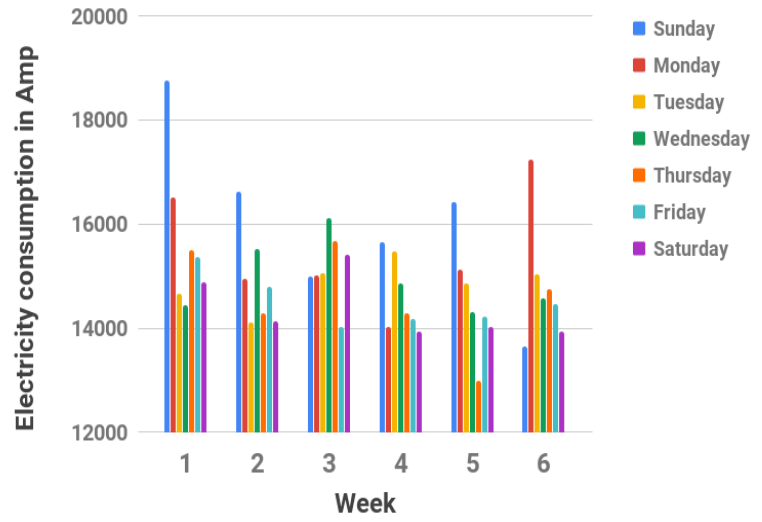

Figure 7. Electricity consumption of water dispenser day wise

Figure 8 represents the usage of electricity at day and night by refrigerator. From the Figure 8 , it is seen that the amount of electricity consumed is greater at night times. An analysis on this can control the usage of refrigerator by the consumer. Figure 9 represents the usage of electricity daily by refrigerator. From the Figure 9, it is seen that the amount of electricity consumed in the weekend is comparatively higher than week days. 


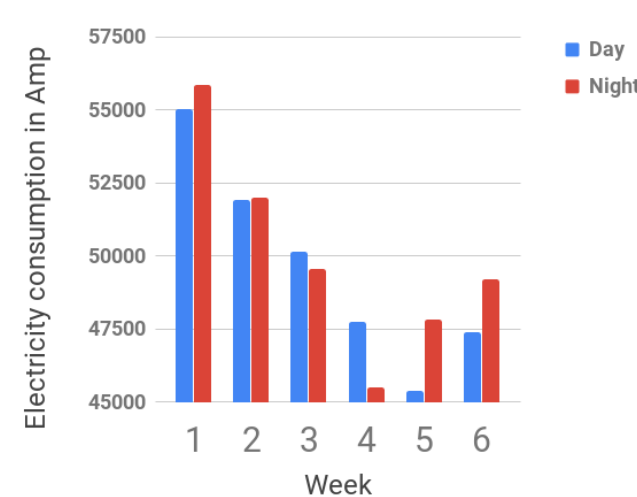

Figure 8. Electricity consumption of refrigerator day and night

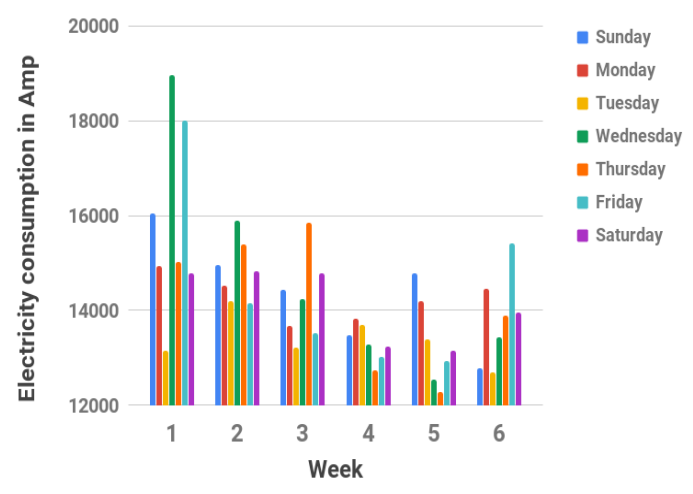

Figure 9. Electricity consumption of refrigerator day wise

\section{CONCLUSION}

In this study, the electricity consumption on household appliance was monitored and analyzed in a single house hold of four members. The study was conducted with two full time working appliances, Refrigerator and water dispenser. The results of the analysis showed the energy consumption on weekends is more compared to the week days. The analysis also showed that the electricity consumption at night falls ahead compared to day time. The introduction of smart systems will help the consumer to monitor and do an analysis of power consumption in order to adjust the usage that will in turn help in lowering the electricity bill.

\section{REFERENCES}

[1] J. Han, et al., "Remote-Controllable and Energy-Saving Room Architecture based on ZigBee Communication," IEEE Trans. On Consumer Electronics, vol. 55, pp. 264-268, 2009.

[2] Y. Bai and C. Hung, "Remote Power On/Off Control and Current Measurement for Home Electric Outlets Based on a Low-Power Embedded Board and ZigBee Communication," Proceedings of the 2008 International Symposium on Consumer Electronics, Algarve, Portugal, 2008.

[3] I. Laicane, et al., "Evaluation of household electricity savings Analysis of household electricity demand profile and user activities," Energy Procedia, vol. 72, pp. 285-292, 2015.

[4] Gils H. C., "Assessment of the theoretical demand response potential in Europe," Energy, vol. 67, pp. 1-18, 2014.

[5] Munkhammar J., et al., "Characterizing probability density distributions for household electricity load profiles from highresolution electricity use data," Applied Energy, vol. 135, pp. 382-390, 2014.

[6] Swan L. G. and Ugursal V. I., "Modeling of end-use energy consumption in the residential sector: a review of modeling techniques," Renewable and Sustainaible Energy Review, vol. 13, pp. 1819-1835, 2009.

[7] Paatero J. V. and Lund P. D., "A model for generating household load profiles," Internation Journal of Energy Resources, vol. 30, pp. 273-290, 2006.

[8] Widen J., et al., "Construction load profiles for household electricity and hot water from time-use data: Modelling approach and validation," Energy and Buildings, vol. 41, pp. 753-768, 2009.

[9] Widén J. and Munkhammar J., "Evaluating the benefits of a solar home energy management system: impacts on photovoltaic power production value and grid interaction," Proceedings of ECEEE summer study, 2013. 